This timely publication may help to remind psychiatrists of the limitations of any approach to the understanding and treatment of psychotic disorders that ignores the inner life and psychodynamics of the individual. It may also remind psychoanalysts and psychoanalytic psychotherapists working in the health service of the urgency of the need to find ways to increase their input to the treatment of psychotic patients, and to improve cooperation with those of their colleagues who adopt a more exclusively biological approach to the task at the expense of psychodynamics.

Hansen, J. B. (ed.) (1993) Crossing the Borders: Psychotherapy of Schizophrenia. Ludvika, Sweden: Dualis Forlag.

\section{MurRay Jackson}

le Pous

St Andre de Roquepertuis

30630 France

\section{Long-term antidepressant treatment in the elderly}

SIR: The Old Age Depression Interest Group (OADIG) (Journal, February 1993, 162, 175-182) reported the results of their important study of continuation and maintenance of antidepressant treatment in depressed elderly subjects. Compared to placebo, dothiepin reduced the risk of a recurrence of depression by two-and-a-half times during the twoyear study. The authors concluded that "elderly patients who recover from a major depressive illness should continue with antidepressant medication for at least two years". While most clinicians would agree with this recommendation for patients with recurrent depression, it is more controversial for the elderly patient with a first episode of depression. Indeed, the recently published NIH Consensus Development conference statement on the diagnosis and treatment of depression in late life recommends only six months of treatment after remission from a first episode of major depression in old age (NIH Consensus Development Panel, 1992).

Sixty per cent of patients in the OADIG study were experiencing their first depressive episode. The authors found that age at first onset of affective disorder did not predict outcome. However, they did not specifically report on the rate of recurrence in the group of patients suffering their first depression. This piece of information would be of particular interest and value. There is evidence from other studies that elderly persons with a first episode of depression are at the same risk of recurrence, within two years of the index episode, as those with recurrent depression (Flint, 1992). A similar finding from the OADIG study would further support the contention that all patients over the age of 60 years with major depression should continue with treatment for a minimum of two years following recovery.

Funt, A. J. (1992) The optimum duration of antidepressant treatment in the elderly. International Journal of Geriatric Psychiatry 7,617-619.

NIH Consensus Development Panel (1992) Diagnosis and treatment of depression in late life. Journal of the American Medical Association, 268, 1018-1024.

Department of Psychiatry

Toronto General Hospital

Toronto, Canada M5G 2C4

Alastair Flint

\section{Child psychiatric syndromes with a somatic} presentation

SIR: Garralda's useful review (Journal, December $1992,161,759-773$ ) missed one important series of papers in the literature on conversion disorder. Seltzer's papers in Family Systems Medicine (Seltzer, $1985 a, b)$ give detailed accounts of the family and cultural background of such patients with a conversion disorder, and offers some helpful therapeutic advice. Nowhere else have I seen a discussion of the personality and environment of childrens' hysteria in such depth, and I recommend these papers to your readers.

Seltzer, W. J. (1985a) Conversion disorder in childhood and adolescence: a familial/cultural approach, part I. Family Systems Medicine, 3, 261-280.

- $(1985 b)$ Conversion disorder in childhood and adolescence, part II. Therapeutic issues. Family Systems Medicine, 3, 397-416.

Child and Family Psychiatric Service

Sebastian Kraemer

The Whittington Hospital

Highgate Hill

London N19 SNF

Distribution of adipose tissue in patients receiving psychotropic drugs

SIR: Stedman \& Welham (Journal, February 1993, $162,249-250$ ) investigated the problem of obesity in long-term female in-patients on psychotropic medication. They found similar levels of obesity to those reported in other studies. Within this context they demonstrated a previously unrecognised problem with central obesity, and they argue for the importance of this finding. 